\title{
Experimental Investigation on Effects of MQL on Surface Finish and Tool Wear in Turning of SAE 1018
}

\author{
Sandeep Kumar ${ }^{1}$, Sukhpal Singh Chatha ${ }^{2}$ and Rutash Mittal ${ }^{3}$ \\ ${ }^{1}$ Tech Student, Department of Mechanical Engineering, MIMIT, Malout, Punjab, India \\ ${ }^{2}$ Assistant Professor, Yadavindra College of Engineering, \\ Punjabi University Guru Kashi Campus, Talwandi Sabo, Punjab \\ ${ }^{3}$ Assistant Professor, Department of Mechanical Engineering, MIMIT, Malout, Punjab, India \\ E Mail: sandeepsukhija71@gmail.com
}

\begin{abstract}
In all machining processes, tool wear is a major problem and it leads to tool failure. In metal industries, the use of cutting fluids affects both employee's health and environmental pollution. But the use of cutting fluids becomes necessary to keep tight tolerances and to maintain the workpiece surface properties without damages. Researchers are trying to reduce the use of coolant lubricant fluids in metal cutting to obtain environmental safety. So, to minimize the use of cutting fluids new cutting techniques are investigated. Minimal quantity of Lubrication (MQL) is a recent technique introduced in machining to obtain less tool wear and environment safety. The minimum quantity lubrication was provided with a spray of mixture of air and vegetable oil at suitable pressure. MQL machining was performed much superior compared to dry and wet machining due to substantial reduction in tool wear and cutting zone temperature and a better surface finish. MQL provides neat and clean environment avoiding health hazards due to smoke, fumes and gases etc. In this study work-piece of SAE 1018 were prepared to investigate their Surface finish under turning with coated tool bits. Wear of nose radius of tool bits were analyzed by SEM which results in less wear in MQL process as compared to flood cooling.
\end{abstract}

Keywords: Minimum Quantity Lubrication (MQL), Scanning Electron Microscope (SEM), Flood Cooling

\section{INTRODUCTION}

In view of green manufacturing, dry machining has drawn much attention from industries recently. Dry machining is eco-friendly in nature but less effective where better surface finish required. Currently industries use very huge amount of metal working fluids which are hazardous to the Environment and workers health. The cutting environment plays very important role in machining. During the cutting operation friction produced between the tool and work-piece which results in huge rise in the tool-chip interface temperature and influences the Surface Quality, Tool life etc.

The need of using less harmful cutting fluids suggested the semi dry lubrication technique. This technique utilizes very least amount of cutting lubricants which leads to economic benefits and reduced machine cleaning time.[2] Semi Dry machining refers to the condition of applying cutting fluid at relatively low flow rates, on order of $2-100 \mathrm{ml} / \mathrm{h}$, as opposed to the conventional way of using either a large quantity [6].

\section{A. Need of Semi Dry Lubrication}

1. NDL uses comparatively very little amount of cutting fluid making it almost dry and clean.

2. The aerosol of the cutting fluid vaporizes quickly removing the heat while making the process clean and environmentally friendly.

3. Semi Dry lubrication gives reduced tool wear, improved tool life and better surface finish as compared to dry and wet machining.

4. No need to wash work pieces [10].

5. Accidents due to large quantities of leaking coolant are avoided.

6. Due to a dry machine, the risk of accidents at work is reduced. [4]

\section{B. Concept of $M Q L$}

Minimum quantity lubrication is an effective semi dry machining techniques as well as an efficient alternative to completely dry and wet cutting conditions from the viewpoint of cost, ecological and human health issues and machining process performance. [12]. MQL is a technique which sprays small amount of cutting fluid $(10-100 \mathrm{ml} / \mathrm{h})$ to the cutting zone area with aid of compressed air. [11]

In high speed machining, conventional cutting fluid fails to penetrate the cutting zone and thus cannot remove the heat effectively. Infect the high cutting pressure in the contact area and small space between chips and tool don't allow the cutting fluid to reach this zone. In order to get a good cooling action the cutting area is generally flooded by lubricant.[1] MQL presents itself as a possible solution for hard turning in achieving slow tool wear while maintaining the cutting forces at reasonable levels.[10] MQL is an ecologically friendly and cost effective method of fluid delivery. [13] The present work experimentally investigates the tool wear and Surface roughness of SAE 1018 at different Speed combinations with constant feed and Depth of Cut by coated carbide insert and compares the effectiveness of MQl and Flood machining. 


\section{METHODOLOGY}

For the present experimental studies, the plain turning was conducted on specimen of SAE 1018 of $36 \mathrm{~mm}$ Diameter and $520 \mathrm{~mm}$ length in the workshop at MIMIT, Malout with Coated Carbide insert under different cooling conditions i.e. Flood Cooling and MQL to study the effects of MQL on Tool wear and surface finish of specimen. The Experimental conditions are given in Table I. The experiment conducted at three different speeds with constant Depth of cut.

The aerosol needs to be supply at high pressure and directed to tool chip interface at high-speed through the nozzle. A MQL delivery system has been designed by considering required conditions. The schematic view of MQL setup is as shown in fig. 1.

TABLE I EXPERIMENTAL CONDITIONS

\begin{tabular}{|l|l|}
\hline Machine Tool & $\begin{array}{l}\text { Lathe Machine (Panther 2 } \\
\text { HP }\end{array}$ \\
\hline Cutting Insert & Coated Carbide- PS08 \\
\hline Work-piece Material and Size & $\begin{array}{l}\text { SAE 1018 (Dia 36 mm, } \\
\text { Length 520 mm) }\end{array}$ \\
\hline Spindle Speed & $288,384,598 \mathrm{rpm}$ \\
\hline Feed Rate & $0.86,0.10,0.11$ \\
\hline Depth of Cut & $0.5 \mathrm{~mm}$ \\
\hline $\begin{array}{l}\text { MQL Supply } \\
\text { Air Pressure }\end{array}$ & $7 \mathrm{bar}$ \\
\hline MQL Flow Rate & $80 \mathrm{ml} / \mathrm{hr}$ \\
\hline Oil Used & Mustard Oil \\
\hline Nozzle Diameter & $2 \mathrm{~mm}$ \\
\hline
\end{tabular}

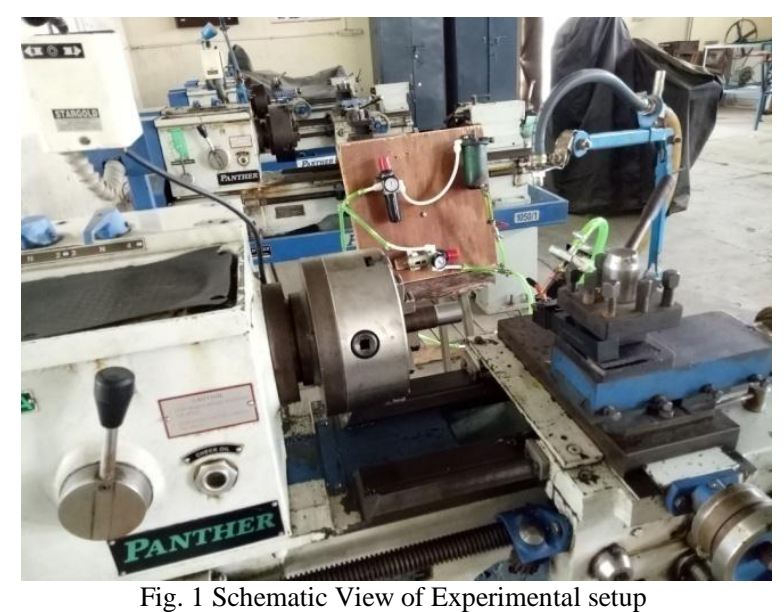

\section{MEASUREMENT OF SURFACE ROUGHNESS AND TOOL WEAR}

Nose wear is important factor for the tool life. Less nose wear of the tool provides the better surface finish. Measurement of the tool wear, the carbide insert was withdrawn after each operation to study the Nose wear under different operations and experimental conditions. The Nose wear of each carbide insert was observed with the help of CMM (Co-ordinate measuring machine) test at $\mathrm{R} \& \mathrm{D}$ centre.

The turned samples of work-piece after all operations were prepared and inspected with Mitutoyo SURFTEST-4 at R\&D Centre Ludhiana. Surface roughness of each workpiece sample was inspected.

\section{RESULTS AND DISCUSSION}

Nose wear is an important factor which affects the tool life and surface roughness. The gradual nose wear caused due to high cutting forces and high interface temperature. In this study different machining environments studied which gives different wear results.

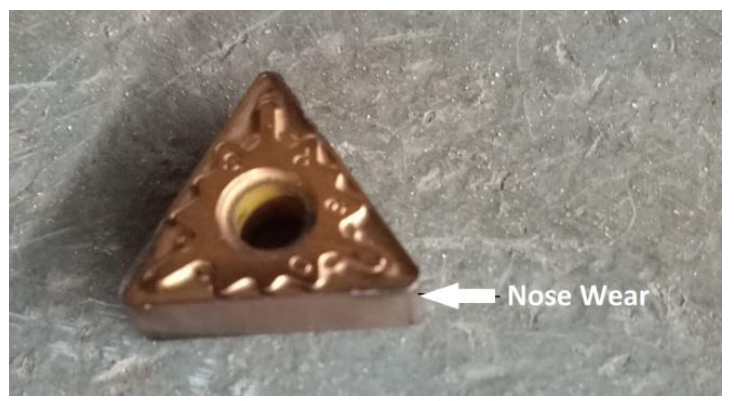

Fig. 2 Coated Carbide bit

The pictorial view of Coated Carbide bit as shown in fig. 2 . This study reveals less Nose wear under MQL machining as compared to flood cooling. The fig. 3 shows the Effect on nose wear in different cooling environment at different speed. From the graph it is proved that the amount of nose wear for the tool in MQL is less as compared to that of flood cooling. It is appeared that MQL increases the tool life.

The experiment was carried out at three different speeds and MQL provides less nose wear and flood cooling gives significant wear of carbide insert. The best result obtained at 384 speed with MQL technique.

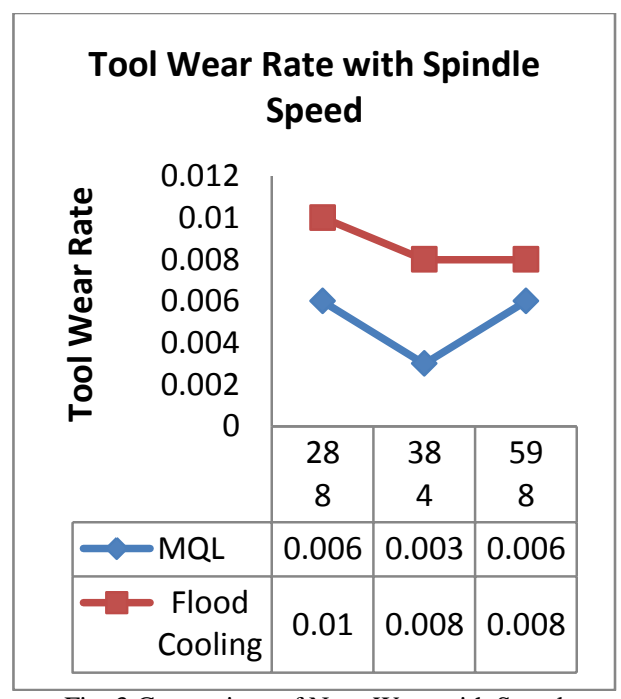

Fig. 3 Comparison of Nose Wear with Speed 
Surface Roughness is also important factor of experimental conditions. To evaluate the machining process performance, Surface roughness were compared under different cutting conditions.

During this study surface roughness has been measure for both MQL and Flood machining. Experiment was carried out at different speed and cutting environment and Surface roughness is measured after each operation. Fig.4 shows the variation in the surface roughness with spindle speed under flood and MQL by mustard oil conditions. As MQL reduced nose wear of cutting tool. Surface roughness also grew very slowly under MQL as compared to flood environment.

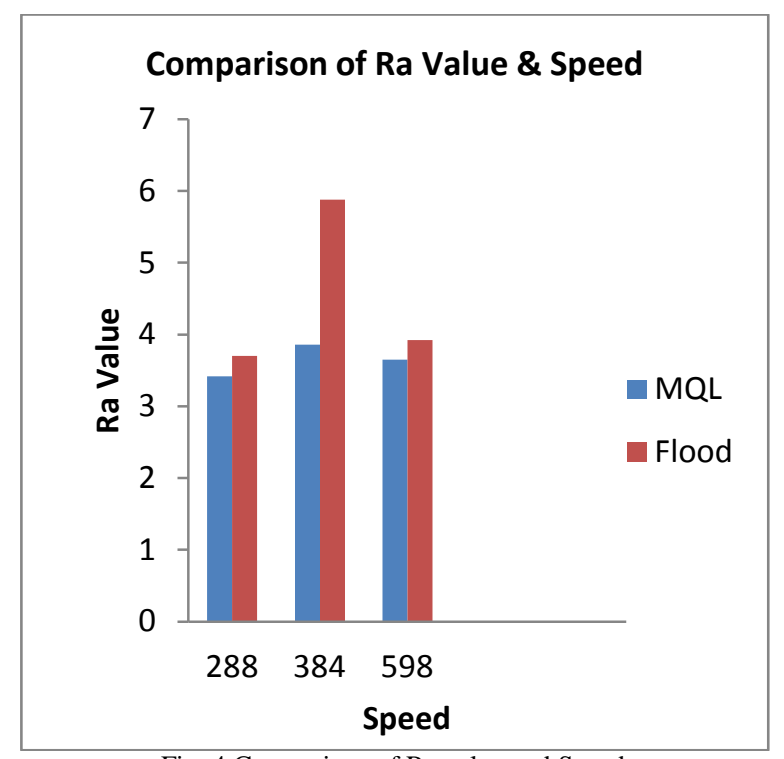

Fig. 4 Comparison of Ra value and Speed

During the MQL cutting environment surface roughness decreases and increases in case of Flood cooling environment.

Fig.4 describes that surface roughness grew faster in flood cooling due to more cutting forces and high interface temperature. Mustard oil in MQL technique gives reduced surface roughness.

\section{CONCLUSION}

The main Aim of this research was to compare the effects of MQL on Tool wear and Surface Roughness in terms of Nose Wear and Surface roughness at suitable cutting conditions. The Experimental results concludes that

1. The Nose wear results obtained by using MQL are better than flood cooling.
2. The surface roughness decreases as cooling provided by using Mustard oil with Compressed air at high pressure.

3. During MQL, minute amount of fumes and oxides produced which is eco-friendly with environment.

4. The cutting performance of MQL operation is better than flood machining.

\section{REFERENCES}

[1] A. Attanasio, M. Gelfi, C. Giardini and C. Remino, "Minimum Quantity Lubrication in Turning: Effect on Tool Wear", Wear, Vol. 260, pp. 333-338, 2006.

[2] M.M.A. KHAN and N.R. DHAR "Performance Evaluation of Minimum Quantity Lubrication by Vegetable oil in term of Cutting Force, Cutting zone temperature, Tool wear, job dimension and Surface finish in turning AISI-1060 Steel", Journal of Zhejiang University SCIENCE A, ISSN;1009-3095, 2006.

[3] Sukhpal singh chatha, Amrit pal, Tarjeet singh. "Performance evaluation of aluminium 6063 drilling under the infulence of nonofluid Minimum Quantity Lubrication", Journal of Cleaner Poduction, Vol. 137, 2016.

[4] Hina Nigar and Faizan Hasan, "A review on minimum quantity lubrication for machining operations", IJTRA, -ISSN: 2320-8163, 2017.

[5] Mohd. Arif I Upletawala and Prof. Tushar Katratwar, "A literature review on various factors affecting Turning Operation", IJETMAS, ISSN 2349-4476, 2016.

[6] Kuan Ming Li and Shih- Yen Chou, "Experimental evaluation of minimum quantity lubrication in near micro-milling", Journal of Materials Processing Technology, doi:10.1016, 2010.

[7] Jadhav J.S, Jadhav B.R., "Experimental study of effect of cutting parameters on cutting force in turning", IJIRAE, ISSN: 2349-2163, 2014.

[8] Arvind Kondekar, S.S. Sarnobat, Swapnil S Kulkarni, "Optimization of turning process parameters through DOE for surface finish and tool wear", IJAERS, ISSN- 2249-8974, 2013.

[9] M.M.A. Khan, M.A.H.Mithu and N.R. Dhar, "Effects of minimum quantity lubrication on turning AISI 9310 alloy steel using vegetable oil based cutting fluid", Journal of Material Processing Technology, 209 5573-5583.

[10] N.R. Dhar, M.W. Islam, S. Islam and M.A.H. Mithu, "The influence of minimum quantity lubrication on cutting temperature, chip and dimensional accuracy in turning AISI -1040 steel", Journal of Material Processing Technology, doi: 10.1016, 2006.

[11] Mohamed Handawi Saad Elmunafi, M.Y. NoorDin and D. Kurniawan, "Tool life of coated carbide cutting tool when turning hardened stainless steel under minimum quantity lubricant using caster oil", Procedia Manufacturing, Vol. 2, pp. 563-567, 2015

[12] M Najitha, M Rahman and K Kadirgama, "Performance of water based $\mathrm{TiO}_{2}$ nanofluid during the minimum quantity lubrication machining of aluminium alloy, AA6061-T6", Journal of Cleaner Production, 2016.

[13] Mohsen Emami, Mohommad Hossein Sadeghi and Ahmed Sarhan, "MQL in Grinding Process of Zirconia Engineering Ceramic", IJMMME, ISSN: 2320-4052, 2013.

[14] Prateek Selopa and, O.S. Bhatia, "Lubrication A review", IJARIIT, ISSN-2454-132X, 2015.

[15] Mohd. Arif I Upletawala and Prof. Tushar Katratwar, "A literature review on various factors affecting Turning Operation", IJETMAS, ISSN 2349-4476, 2016. 